\title{
The Effect of $\mathrm{CuO}$ addition on low temperature co-firing PZT ferroelectric ceramics in multilayer device application
}

\author{
Xiumei Shi ${ }^{1,2 a}{ }^{*}$, Tao Zeng ${ }^{3, b}$, Hong Cui ${ }^{1, c}$, Lijun Zhang ${ }^{2, d}$ \\ ${ }^{1}$ Northwestern Polytechnical University, Xi'an ,710072 China \\ ${ }^{2}$ Inner Mongolia Metal Material Research Institute, Baotou,014030,China \\ ${ }^{3}$ Shanghai Research Institute of Materials, Shanghai, 200437, China \\ asxm4083@163.com, ${ }^{\mathrm{b}}$ zengtao@shiep.edu.cn, ${ }^{\mathrm{c}}$ cuih1969@163.com, ${ }^{\mathrm{d}}$ zhanglijun_nb@126.com
}

Keywords: PZT95/5 ceramics; ferroelectric properties; CuO; piezoelectric properties

Abstract. Low-temperature sintering of $\mathrm{Pb}_{0.995} \mathrm{Cd}_{0.005}\left(\mathrm{Zr}_{0.965} \mathrm{Ti}_{0.035}\right) \mathrm{O}_{3}$ ceramics was investigated using $\mathrm{CuO}$ as a sintering aid. Effect of $\mathrm{CuO}$ addition on the sinter ability, microstructure, and electric properties of PZT ceramics were systematically studied. The addition of $\mathrm{CuO}$ significantly promoted the densification of PZT and reduced the sintering temperature of PZT ceramics to $1050^{\circ} \mathrm{C}$. PZT ceramics with $\mathrm{CuO}$ addition were sintered at $1150^{\circ} \mathrm{C}$ and exhibit a high density of $7.6 \mathrm{~g} / \mathrm{cm}^{3}$, which corresponds to the approximately $96 \%$ theoretical density. And the optimized value for the piezoelectric coefficient $\mathrm{d}_{33}$ of $66 \mathrm{pC} / \mathrm{N}$ was obtained for $0.05 \% \mathrm{CuO}$-added PZT ceramics, which shows a great promise for multilayer actuator applications.

\section{Introduction}

PZT95/5 ceramics is one of the most useful functional materials; it is not only used as excellent driven material, but also as sensitive transducer material. Because of excellent ferroelectric capability and large electromechanical coupling coefficient, it fits well with the designed requirements of multilayer piezoelectric device, and has been widely used in many fields such as micro-electronics, photoelectron systems and high-voltage power supply components ${ }^{[1,2]}$. For these applications, several pieces of ceramics need to be stacked in series to enhance the output electric current. Co-firing multilayer PZT95/5 ceramics is a promising way to prevent the multilayer piezoelectric devices from dielectric breakdowns under shock compression. During fabrication of multilayer piezoelectric devices, co-firing of ceramic and internal metallic electrodes is very critical [3]. Generally, silver and even silver-palladium alloy which are the most commonly used for internal electrode for their high conductivity and low cost have a problem of migration when the sintering temperature is above $960^{\circ} \mathrm{C}^{[4]}$. However, the sintering temperatures of conventional lead-based piezoelectric ceramics are exceedingly higher than $1200^{\circ} \mathrm{C}^{[5,6]}$. Therefore, it is very important to decrease the sintering temperature of PZT95/5 ceramics for multilayer device application. The addition of low-melting-point materials is a promising way to lower the sintering temperature.

The effects of different additions such as $\mathrm{WO}_{3}, \mathrm{MnO}_{2}, \mathrm{LiBiO}_{2}$ et al. with different contents on the properties of low temperature sintering of PZT based ceramics have been investigated ${ }^{[7,8]}$. The results showed that the addition of $\mathrm{WO}_{3}$ and $\mathrm{MnO}_{2}$ can improve the sintering density and electric properties, but samples still are sintered at $1100^{\circ} \mathrm{C}$. The addition of $\mathrm{LiBiO}_{2}$ could make samples sintered at $1000^{\circ} \mathrm{C}$, but the electric properties had bad decline ${ }^{[9,10]}$. So it is critical to seek a method to lower the sintering temperature while maintaining the ferroelectric properties. In our present work, low temperature sintering of $\mathrm{Pb}_{0.995} \mathrm{Cd}_{0.005}\left(\mathrm{Zr}_{0.965} \mathrm{Ti}_{0.035}\right) \mathrm{O}_{3}$ ceramics with $\mathrm{CuO}$ additives were systematically investigated. It was found that $\mathrm{CuO}$ significantly reduced the sintering temperature to $1050^{\circ} \mathrm{C}$ while the density was $7.65 \mathrm{~g} / \mathrm{cm}^{3}$, and electric properties could be maintained. 


\section{Experimential procedure}

\section{Materials}

The ceramics of $\mathrm{Pb}_{0.995} \mathrm{Cd}_{0.005}\left(\mathrm{Zr}_{0.965} \mathrm{Ti}_{0.035}\right) \mathrm{O}_{3}+1 \% \mathrm{wtNb}_{2} \mathrm{O}_{5}+\mathrm{xwt} \% \mathrm{CuO}(\mathrm{x}=0,0.05,0.1,0.15,0.2)$ were prepared with traditional solid-state method. Reagent-grade raw materials of $\mathrm{Pb}_{3} \mathrm{O}_{4}, \mathrm{ZrO}_{2}, \mathrm{TiO}_{2}$, $\mathrm{CdO}, \mathrm{CuO}$ were weighed by mole ratio and mixed together by ball milling for $8 \mathrm{~h}$, subsequently dried and filtered through a net of 40 meshes. The mixture was calcined at $850^{\circ} \mathrm{C}$ for $2 \mathrm{~h}$. Pellets with the diameter of $15 \mathrm{~mm}$ were pressed and sintered in a sealed alumina crucible at various temperatures for $4 \mathrm{~h}$. And for the electrical property measurement, sintered samples were machined into $\varphi 15 \mathrm{~mm} \times 1 \mathrm{~mm}$ disks and coated with silver paste to form electrodes.

\section{Procedure}

The phase structures of specimens were examined by X-ray diffraction (XRD) using CuKa radiation (D/MAX-2550; Rigaku, Tokyo, Japan). Microstructure of ceramics were observed by scanning electron microscopy (SEM, TM3000; Hitachi, Tokyo, Japan). The density was determined by Archimedes method. The temperature-dependent dielectric properties at $1 \mathrm{kHz}$ were obtained using a LCR meter (Hp4284A; Hewlett-packard, Japan). The polarization-electric field (P-E) behavior loops were measured by a ferroelectric tester (TF Analyzer 2000; aix-ACCT, Aachen, Germany). The piezoelectric coefficient $d_{33}$ was measured using a quasi-static $d_{33}$-meter(Model Zj-3; Institute of Acoustics, Beijing, China) after samples were polarized in silicon oil bath for 30 minutes.

\section{Result and discussion}

\section{Microstructure}

The XRD patterns of $\mathrm{Pb}_{0.995} \mathrm{Cd}_{0.005}\left(\mathrm{Zr}_{0.965} \mathrm{Ti}_{0.035}\right) \mathrm{O}_{3}+1 \%$ wtNb $\mathrm{O}_{5}+$ xwt $\% \mathrm{CuO}$ ceramics with $0.05 \leq \mathrm{x} \leq 0.2$ sintered at $1050^{\circ} \mathrm{C}$ for $4 \mathrm{~h}$ shows presence of only a main pure perovskite phase and no secondary phase(Fig. 1) .

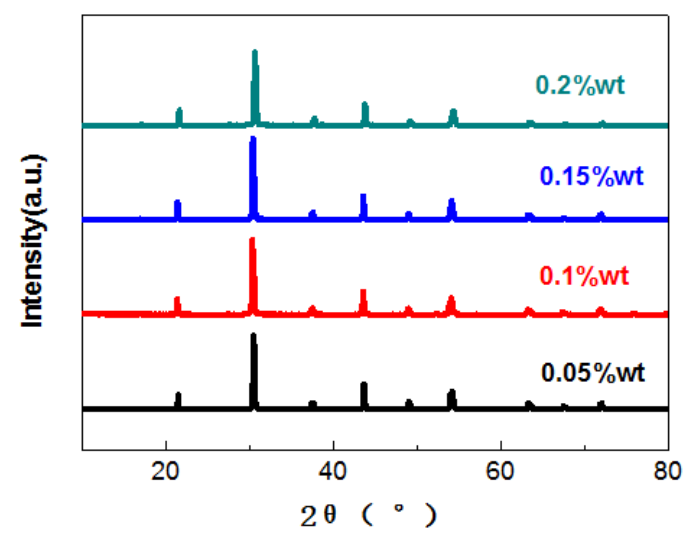

Fig. 1. X-ray diffraction patterns of $\mathrm{Pb}_{0.995} \mathrm{Cd}_{0.005}\left(\mathrm{Zr}_{0.965} \mathrm{Ti}_{0.035}\right) \mathrm{O}_{3}$ with different amounts of $\mathrm{CuO}$ additive sintered at $1050^{\circ} \mathrm{C}$ for $4 \mathrm{~h}$ : (a) $\mathrm{x}=0.05$, (b) $\mathrm{x}=0.1$, (c) $\mathrm{x}=0.15$, (d) $\mathrm{x}=0.2$

The SEM images of $\mathrm{Pb}_{0.995} \mathrm{Cd}_{0.005}\left(\mathrm{Zr}_{0.965} \mathrm{Ti}_{0.035}\right) \mathrm{O}_{3}+1 \%$ wtNb $\mathrm{O}_{5}+\mathrm{xwt} \% \mathrm{CuO}$ ceramics with $0.05 \leq \mathrm{x} \leq 0.2$ sintered at $1050^{\circ} \mathrm{C}$ are given in Fig. 2. Fig. 2 a presents the sample with $0 \% \mathrm{CuO}$ with small and uniformly distributed pores. Microstructures of samples with $0.05 \%, 0.1 \%, 0.15 \%$ and 0.2 wt $\%$ $\mathrm{CuO}$ are shown in Fig.2(b, c, d and e). Uniform sized grains with a clear grain boundary are visible in these samples. And microstructure becomes denser and the grains grow bigger as the $\mathrm{CuO}$ content increased. It was obvious that introduction of $\mathrm{CuO}$ content promoted the densification during sintering of $1050^{\circ} \mathrm{C}$, which was attributed to the liquid phase sintering. 


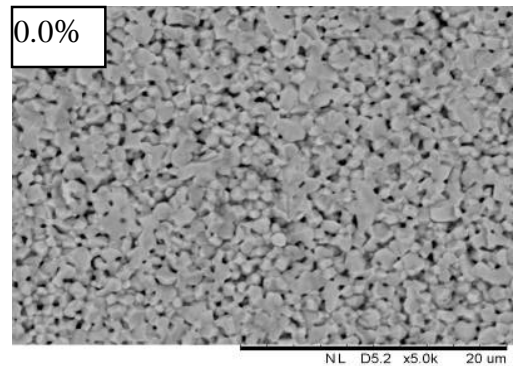

(a)

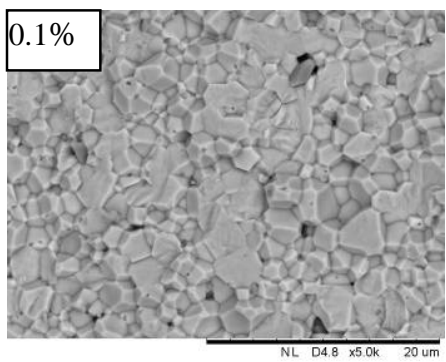

(c)

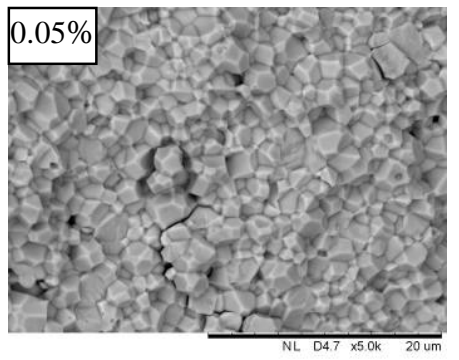

(b)

Fig. 2 SEM images of PZT ceramics with different contents of $\mathrm{CuO}$ additive sintered at $1050^{\circ} \mathrm{C}$ : (a) $\mathrm{x}=0.0$, (b) $\mathrm{x}=0.05$, (c) $\mathrm{x}=0.1$, (d) $\mathrm{x}=0.15$, and (e) $\mathrm{x}=0.2$

\section{Bulk Density}

The density of $\mathrm{Pb}_{0.995} \mathrm{Cd}_{0.005}\left(\mathrm{Zr}_{0.965} \mathrm{Ti}_{0.035}\right) \mathrm{O}_{3}$ ceramics with varying addition of $\mathrm{CuO}$ in the range of $0.05 \%-0.2 \%$ is shown in Fig. 3. The PZT95/5 ceramic could be fully densified with the $0.1 \mathrm{wt} \%$ addition of $\mathrm{CuO}$ at sintering temperatures $1050{ }^{\circ} \mathrm{C}$, which exhibited a high density of $7.65 \mathrm{~g} / \mathrm{cm}^{3}$ corresponding to $96 \%$ theoretical density. The results confirm that $\mathrm{CuO}$ addition significantly enhances the densification and reduces the sintering temperature of PZT ceramics.

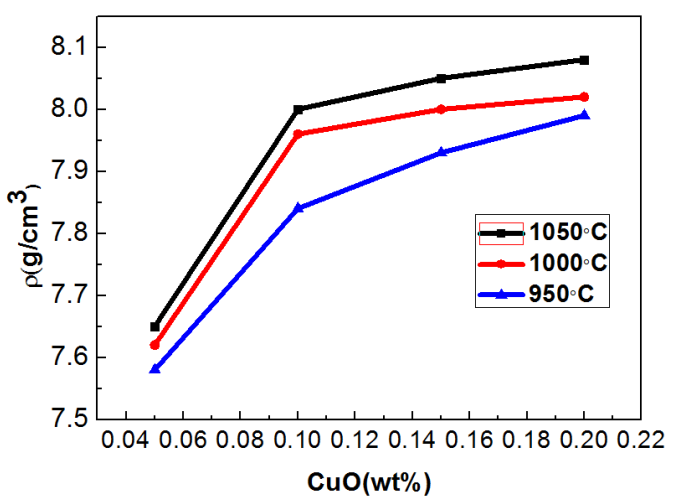

Fig. 3 the bulk density of PZT ceramics with different contents of $\mathrm{CuO}$ additive sintered at $950^{\circ} \mathrm{C}, 1000^{\circ} \mathrm{C}$ and $1050^{\circ} \mathrm{C}$

\section{Ferroelectric and Piezoelectric Properties}

The changes in piezoelectric coefficient $\mathrm{d}_{33}$ with varying addition of $\mathrm{CuO}$ in the range of $0.05 \%-0.2 \%$ are shown in Fig. 4 . It is observed that the piezoelectric coefficient $\mathrm{d}_{33}$ decreases linearly with an increase of $\mathrm{CuO}$ content from $0.05 \%$ to $0.15 \mathrm{wt} \%$. Furthermore, increasing the amount of $\mathrm{CuO}$ from $0.15 \mathrm{wt} \%$ to $0.2 \mathrm{wt} \%$, then the piezoelectric coefficient $\mathrm{d}_{33}$ began to increase slightly. This demonstrates that the addition of $\mathrm{CuO}$ may produce the positive and negative influence on PZT ceramics, on the one hand, it will help to reduce the sintering temperature, on the other hand, the electric properties had bad decline with the increased addition of $\mathrm{CuO}$. The optimized value for $\mathrm{d}_{33}$ of $66 \mathrm{pC} / \mathrm{N}$ was obtained for $0.05 \% \mathrm{CuO}$-added PZT ceramics. 


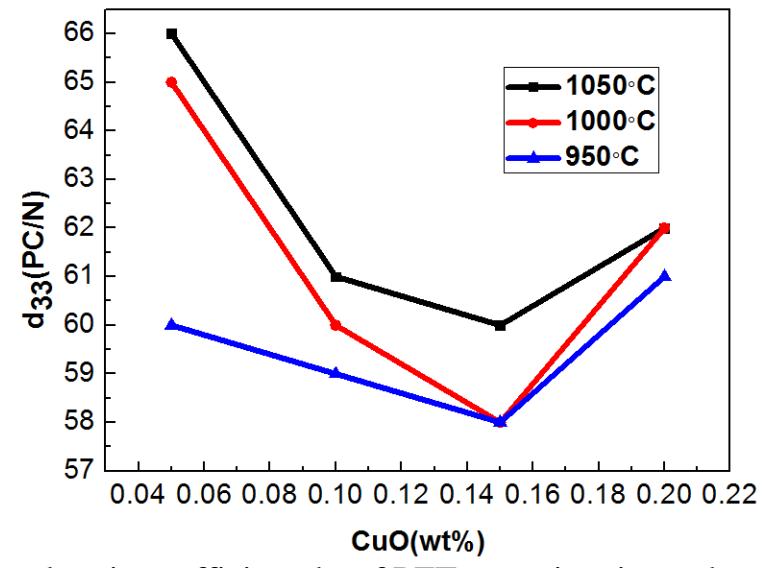

Fig.4 the piezoelectric coefficient $\mathrm{d}_{33}$ of PZT ceramics sintered at different temperatures

The P-E hysteresis loops of PZT ceramics with $\mathrm{CuO}$ addition sintered at temperature $1050^{\circ} \mathrm{C}$ for $4 \mathrm{~h}$ are shown in Fig.5. It is obvious that the addition of $\mathrm{CuO}$ is evidently helpful for the ferroelectric properties of PZT ceramics sintered at $1050^{\circ} \mathrm{C}$. It can be seen that the remnant polarization $\mathrm{Pr}$ increased but the coercive field Ec doesn't change when increasing the amount of $\mathrm{CuO}$. The maximum $\mathrm{Pr}$ is about $42 \mu \mathrm{C} / \mathrm{cm}^{2}$ is achieved in $0.05 \mathrm{wt} \% \mathrm{CuO}$-added sample, which should be attributed to the highly dense microstructure of pure perovskite phase.

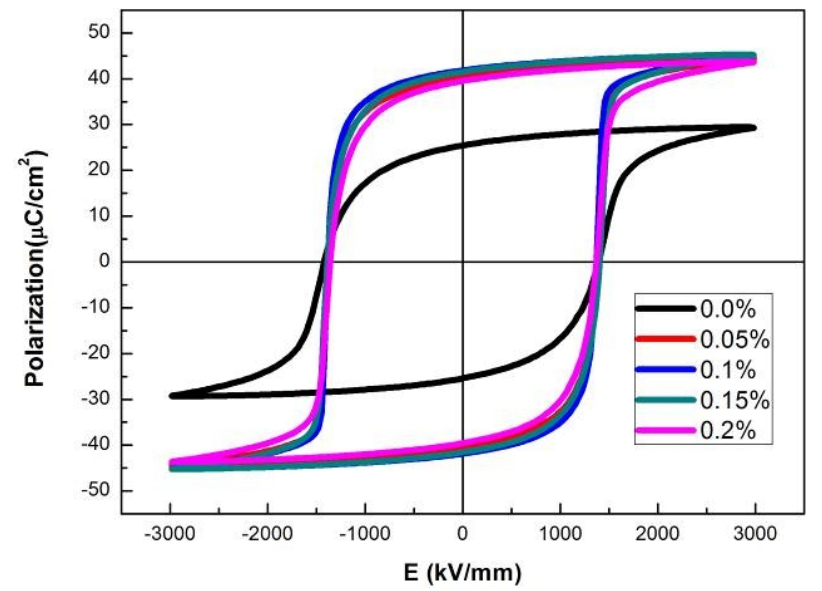

Fig. 5 Polarization-electric field (P-E) hysteresis loops of PZT with different amounts of $\mathrm{CuO}$ additive sintered at $1050^{\circ} \mathrm{C}$

Table 1 presents data on the electric properties of $\mathrm{Pb}_{0.995} \mathrm{Cd}_{0.005}\left(\mathrm{Zr}_{0.965} \mathrm{Ti}_{0.035}\right) \mathrm{O}_{3}$ ceramics sintered samples at $1050^{\circ} \mathrm{C}$ with varying addition of $\mathrm{CuO}$. The results showed that the PZT ceramics has the optimum properties, that dielectric constant $\left(\varepsilon^{\mathrm{T}}\right)$, piezoelectric coefficient $\left(\mathrm{d}_{33}\right)$, and loss tangent $(\tan \delta)$ achieve $279,66 \mathrm{pC} / \mathrm{N}$ and 1.9 respectively, under the sintering temperature of $1050^{\circ} \mathrm{C}$ with the $0.05 \mathrm{wt} \%$ of $\mathrm{CuO}$-added.

Table 1. Electric properties of $\mathrm{Pb}_{0.995} \mathrm{Cd}_{0.005}\left(\mathrm{Zr}_{0.965} \mathrm{Ti}_{0.035}\right) \mathrm{O}_{3}$ with different amounts of $\mathrm{CuO}$ sintered at $1050^{\circ} \mathrm{C}$

\begin{tabular}{ccccc}
\hline $\mathrm{X}(\mathrm{wt} \%)$ & Sintering temperature $\left({ }^{\circ} \mathrm{C}\right)$ & $\varepsilon^{\mathrm{T}}$ & $\operatorname{tg} \delta$ & $\mathrm{d}_{33}(\mathrm{pC} / \mathrm{N})$ \\
\hline 0 & 1050 & 268 & 2.1 & 65 \\
0.05 & 1050 & 279 & 1.9 & 66 \\
0.1 & 1050 & 284 & 1.7 & 61 \\
0.15 & 1050 & 296 & 2.8 & 60 \\
0.2 & 1050 & 339 & 2.2 & 62 \\
\hline
\end{tabular}




\section{Conclusion}

The $\mathrm{Pb}_{0.995} \mathrm{Cd}_{0.005}\left(\mathrm{Zr}_{0.965} \mathrm{Ti}_{0.035}\right) \mathrm{O}_{3}$ ceramics were fabricated by conventional solid-state sintering method. And $\mathrm{CuO}$ was used as a sintering aid which significantly reduced the sintering temperature to $1050^{\circ} \mathrm{C}$, and meanwhile, the electric properties were improved. Sample with $\mathrm{CuO}$-added PZT ceramics sintered at $1050{ }^{\circ} \mathrm{C}$ exhibited a high density of $7.65 \mathrm{~g} / \mathrm{cm}^{3}$, which corresponds to the relative density of approximately 96\%. The results showed that the PZT ceramics has achieved the optimized properties, that dielectric constant $\left(\varepsilon^{T}\right)$, piezoelectric coefficient $\left(\mathrm{d}_{33}\right)$, and loss tangent $(\tan \delta)$ achieve 279,66 $\mathrm{pC} / \mathrm{N}$ and 1.9 , respectively under the sintering temperature of $1050^{\circ} \mathrm{C}$ with the $0.05 \mathrm{wt} \%$ of $\mathrm{CuO}$-added.

\section{Acknowledgments}

This work was supported by the natural Science Foundation of Ningbo Science and Technology Department, 201601HJ-B01194 and by the National Basic Research Program of China(973 Program) No.2014CB660812.

\section{References}

[1] Jaffe B, Cook W R, Jaffe H. Piezoelectric Ceramics, Academic Press, London, 1971

[2] Haertling G H. Ferroelectric ceramics: history and technology, J. Am. Ceram, 1999, 82(4): 797-818

[3] Hall D A, Evans J D S, Covey-Crump S J, et al. Effects of super-imposed electric field and porosity on the hydrostatic pres-sure-induced rhombohedral to orthorhombic martensitic phase transformation in PZT95/5 ceramics, J. Acta Mater., 2010, 58(20): 6584-6591

[4] Li Wang, Chaoliang Mao and Xianlin Dong et al., Effect of $\mathrm{CuO}$ addition on the microstructure and electric properties of low-temperature sintered 0.25PMN-0.40PT-0.35PZ ceramics, J.Am. Ceram. Soc., 96 (2013)24-27

[5] Lysne P C. Dielectric properties of wave-compressed PZT95/5, J. Appl. Phys., 1977, 48(3): 1020-1023

[6] Lysne P C, Percival C M, Electric energy generation by compression of ferroelectric ceramics: normal-mode. response of PZT95/5, J. Appl. Phys, 1975, 46(4): 1519-1525

[7] G. H. Haertling and C. E. Land, Hot-pressed $(\mathrm{Pb}, \mathrm{La})(\mathrm{Zr}, \mathrm{Ti}) \mathrm{O}_{3}$ ferroelectric ceramics for electrooptic applicaitons, J. Journal of the American Ceramic Society, 54(1971): 1-11

[8] K. Uchino. Ferroelectric Devices[M], New York: Marcel Dekker Inc., 2000

[9] G.F. Fan, M.B. Shi and F. Liang et al., Effects of $\mathrm{Li}_{2} \mathrm{CO}_{3}$ and $\mathrm{Sm}_{2} \mathrm{O}_{3}$ additives on low-temperature sintering and piezoelectric properties of PZN-PZT ceramics, J. Eur. Ceram. S. 34 (2014) 23-28

[10] Y. Zeng, Y. Fei and J. Yi et al.,Effects of $\mathrm{Bi}_{2} \mathrm{O}_{3}-\mathrm{Li}_{2} \mathrm{CO}_{3}$ additions on dielectric and pyroelectric proper-ties of $\mathrm{Mn}$ doped $\mathrm{Pb}\left(\mathrm{Zr}_{0.9} \mathrm{Ti}_{0.1}\right) \mathrm{O}_{3}$ thick films, J.Ceram. Inter. 39 (2013)3709-3714. 